\title{
Immediate Resolution of Hemispatial Neglect and Central Post-Stroke Pain After Perispinal Etanercept: Case Report
}

\author{
Edward Tobinick ${ }^{1}$ (D)
}

Published online: 22 October 2019

(c) The Author(s) 2019

\section{Introduction}

Neglect as a consequence of right brain damage has been recognized at least since J. Hughlings Jackson's 1876 case report [1]. It was later appreciated that impairment in brain functional connectivity and resulting brain network dysfunction ('connectopathy', 'disconnection syndrome') underlies hemispatial neglect, a common sequela of right hemispheric stroke [2, 3]. A variety of bedside tests have been found useful as a measure of hemispatial neglect, including the Clock-Drawing Test [4]. The signature pattern of hemispatial neglect seen after right brain damage with the ClockDrawing Test is a clock face, drawn from memory, lacking numerals in its left half, which has been termed neglect of the left hemispace [5] (Fig. 1a).

Advanced brain imaging methods, including functional magnetic resonance and positron emission tomography (PET), allow the in vivo assessment of functional connectivity and neuroinflammation, respectively. These imaging methods have expanded our understanding of post-stroke neuroinflammation. A growing body of evidence suggests that stroke may result in persistent global brain inflammation and that neuroinflammation may impair brain functional connectivity [2, 3, 6-12]. Neuroinflammation after stroke involves microglial activation $[9,12]$. Elevated levels of the cytokine tumor necrosis factor (TNF) in the brain have been implicated in a wide range of brain disorders [13].

Elevated levels of TNF may adversely affect brain network function because TNF's normal physiological roles include its function as a neuromodulator and gliotransmitter

Electronic supplementary material The online version of this article (https://doi.org/10.1007/s40261-019-00864-8) contains supplementary material, which is available to authorized users.

Edward Tobinick

nrimed@gmail.com

1 Institute of Neurological Recovery, 1877 S. Federal

Highway, Suite 110, Boca Raton, FL 33432, USA that modulates synaptic scaling and synaptic strength, and regulates the tripartite synapse [9, 11, 14, 15]. Biologics targeting TNF have become one of most widely used therapeutics in modern medicine. One such human therapeutic is etanercept, a recombinant fusion protein that potently and selectively inhibits the biological activity of TNF. In basic science models, etanercept has been found to reduce microglial activation and ameliorate neurological dysfunction [7-11, 16]. More recently, in addition to its ability to rapidly reduce chronic post-stroke neurological dysfunction when administered by perispinal injection, etanercept was shown to improve neurological outcomes in six different experimental models of stroke $[9,11,16]$.

In contrast to its rapid brain effects when injected perispinally, etanercept has difficulty crossing the blood-brain barrier in therapeutic quantities when administered systemically $[9,11,14,16,17]$. To avoid the trauma associated with invasive methods of brain delivery, such as intracerebroventricular injection, a new method of drug delivery was needed to facilitate the use of etanercept for brain disorders [9, 11, 14-17]. Perispinal administration was designed as a novel method to enhance delivery of etanercept and other large molecules to the brain via the cerebrospinal venous system (CSVS) (Fig. 2) [6, 9, 11, 14-18].

The CSVS consists of the interconnected cerebral and spinal venous systems, a unique, large capacity, essentially valveless venous network within which bi-directional blood flow occurs, including retrograde blood flow from the spinal venous blood into the brain $[11,16,18]$. Venous drainage of the anatomical region posterior to the spine is accomplished by the external vertebral venous plexus, the most superficial component of the CSVS [11, 16, 18]. The external vertebral venous plexus drains into the internal vertebral venous plexus, which itself drains, and drains into the cerebral venous system $[11,16,18]$. Perispinal injection of etanercept delivers etanercept into the catchment area of the external vertebral venous plexus, thereby enabling etanercept to 
Fig. 1 Clock-drawing test a immediately before perispinal etanercept, and b 30 min after perispinal etanercept
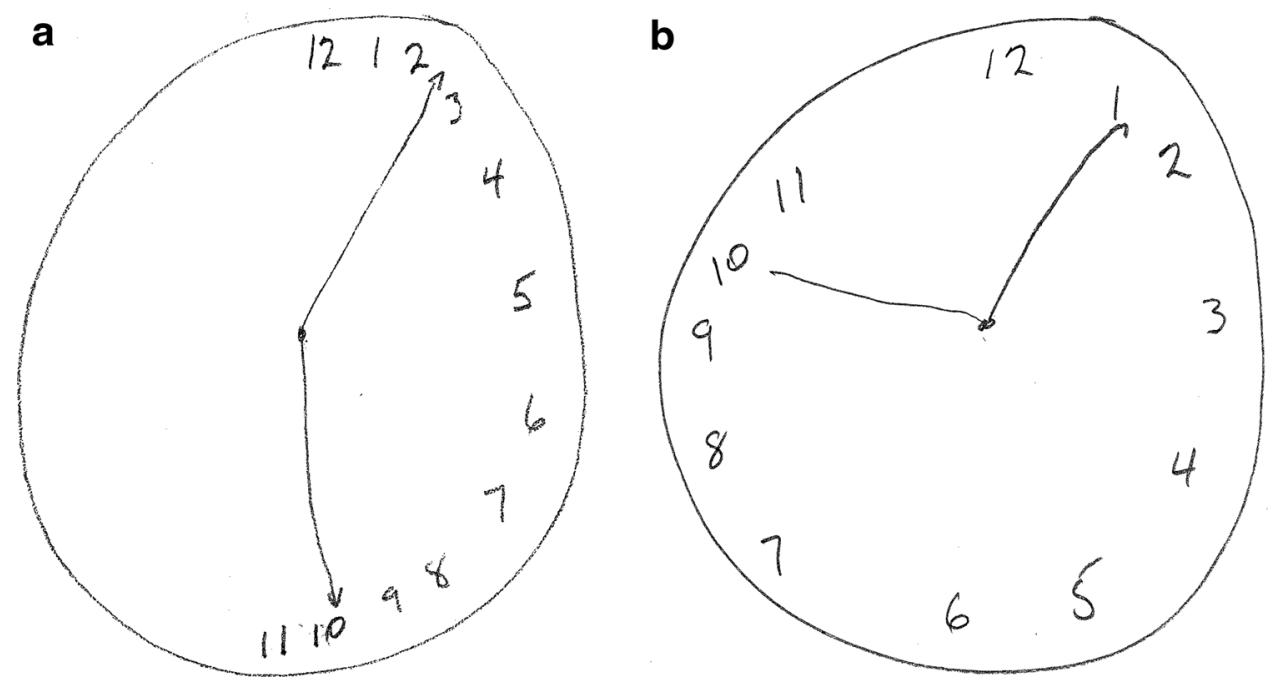

bypass the blood-cerebrospinal fluid barrier and reach the brain [6-11, 13-19].

In an animal model, perispinal administration has been shown to rapidly deliver radiolabeled etanercept into the choroid plexus and cerebrospinal fluid using PET (Fig. 3) [17].

More recently, in another animal model, perispinal administration of a TNF antibody was shown to deliver the antibody into the choroid plexus and to have favorable brain effects, alleviating the sensory and affective components of neuropathic pain [19].

Perispinal etanercept is an emerging treatment for chronic, post-stroke neurological dysfunction, that has been used clinically for more than 8 years and is currently the subject of multiple randomized, placebo-controlled trials underway or in development $[7-9,11,14]$. In stroke, the widespread pattern of rapid neurological improvement seen after perispinal etanercept has been attributed to improvement in functional connectivity due to neutralization of excess TNF [11]. Rapid improvement in clock drawing in a patient with Alzheimer's disease after perispinal etanercept has previously been reported, but improvement in the Clock-Drawing Test in post-stroke patients after perispinal etanercept has not yet been published [6].

\section{Case Report}

A 59-year-old man presented to the clinic 16 years after a right middle cerebral artery stroke caused malignant cerebral edema and coma for 1 week, requiring decompressive craniectomy and subsequent cranioplasty. The stroke resulted in chronic left hemiparesis; left hemispatial neglect; visuospatial dysfunction; left sensory loss involving his left upper extremity, left rib cage and left lower extremity; left

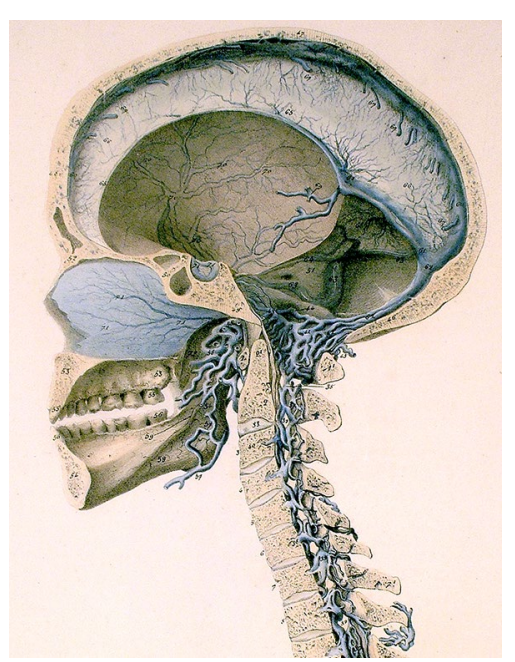

Fig. 2 Cerebrospinal venous system. Detail of plate 5 from Breschet [26]. Courtesy of the Sidney Tobinick collection, modified from the original

cold allodynia; cognitive dysfunction, including impaired short-term memory and difficulty with calculations; impulsiveness; chronic post-stroke fatigue; and spasticity. He also reported having constant, intractable post-stroke pain every hour of every day for the entire 16 years after his stroke, involving his left shoulder, left forearm, and entire left lower extremity. He required a left ankle foot orthosis and a singlepoint cane to ambulate.

Immediately prior to treatment, examination revealed a left hemiparesis, left-sided spasticity, left sensory loss involving both the left upper and lower extremities, cold allodynia on the left upper extremity, cognitive dysfunction (Montreal Cognitive Assessment score =19/30), Fatigue Assessment Scale Score [20] of 24/50, and chronic left-sided 


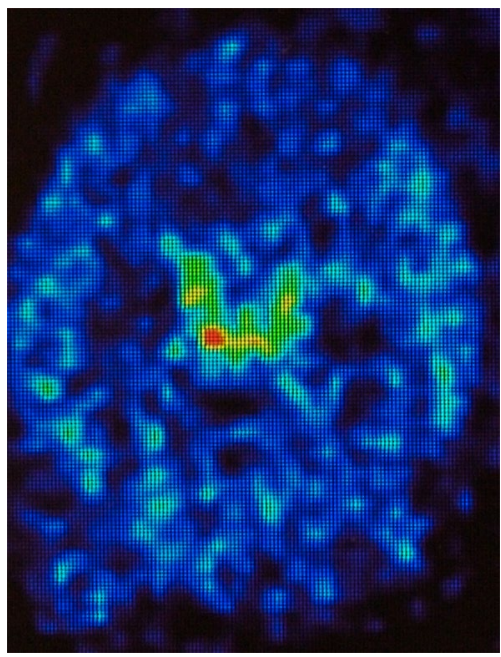

Fig. 3 PET image showing intraventricular delivery of radiolabeled etanercept after perispinal injection. Transverse section of a living rat brain following perispinal extrathecal administration of Cu64-DOTAetanercept, imaged 5-10 min following perispinal injection. Note enhanced signal in the choroid plexus and cerebrospinal fluid within the cerebral ventricles. Modified from Tobinick et al. [17], used under the terms of the Creative Commons Attribution License 2.0. PET positron emission tomography

pain (central post-stroke pain) assessed by the patient as $5 / 10$ in severity on a $0-10$ scale. Walking 20 meters took $58 \mathrm{~s}$. The Five Times Sit-to-Stand test required $27 \mathrm{~s}$ to complete with assist from his right arm. There was prominent left hemispatial neglect, as measured by the Clock-Drawing Test (Fig. 1a). As standard procedure in our medical practice, a Clock-Drawing Test is administered immediately before and within 30 min after treatment. As part of the Clock-Drawing Test, the patient is verbally instructed to 'draw a big round clock, with all of the numbers on it'. After the clock has been drawn, the patient is then verbally instructed to 'make the clock say 10 past 11 '.

After informed consent was obtained, etanercept $25 \mathrm{mg}$ was administered by perispinal injection, followed by Trendelenburg positioning, as previously described [10]. Within $10 \mathrm{~min}$, the patient reported that his chronic left-sided post-stroke pain was gone. Within $30 \mathrm{~min}$ after etanercept administration, the patient reported a complete absence of his chronic left-sided pain, a reduction in spasticity, and improvements in gait, balance, the ability to turn to the left, and the ability to perceive the position of his left foot. A repeat Clock-Drawing Test performed $30 \mathrm{~min}$ after perispinal etanercept injection no longer showed left hemispatial neglect (Fig. 1b). Seventeen days after treatment, the patient reported, by telephone, his neurological improvements had been maintained, with complete absence of pain, absence of allodynia, and improved peripheral vision. His report of reduced fatigue was supported by his Fatigue Assessment Score, which remained reduced by 7 points, measured as
17/50, at both 1 and 2 months after treatment. Eleven months after receiving his single $25 \mathrm{mg}$ dose of perispinal etanercept, the patient reported sustained neurological improvement, when reached by telephone. He specifically reported that his previously chronic and intractable post-stroke pain that had immediately resolved after receiving perispinal etanercept had never returned. A movie file documents this patient's clinical response to perispinal etanercept treatment in more detail (see Online Resource 1, video before and after perispinal etanercept, 16 years after stroke).

We have observed multiple additional patients with left hemispatial neglect and chronic post-stroke neurological dysfunction who have had rapid resolution of left hemispace neglect measured by the Clock-Drawing Test after a single perispinal etanercept injection. In addition, while using perispinal etanercept over the course of nearly 9 years, we have observed many patients experience immediate improvement in central post-stroke pain after perispinal etanercept, and have previously discussed the scientific rationale for this result [7-11].

\section{Discussion and Conclusions}

Evidence that perispinal etanercept had the potential to improve chronic brain dysfunction was first published in 2006 [15]. The first report of rapid improvement in chronic post-stroke neurological dysfunction following perispinal etanercept was published in 2011 [7]. A 2012 observational study involving 617 patients treated with perispinal etanercept for chronic post-stroke neurological dysfunction included mention of a single patient with improvement in hemispatial neglect, beginning $2 \mathrm{~h}$ after perispinal etanercept was administered, but changes in clock drawing were not reported [8]. This is the first report and documentation of immediate improvement in hemispatial neglect, as measured by the Clock-Drawing Test, in a patient with chronic, intractable hemispatial neglect following perispinal etanercept administration.

Improvement in cognitive function within minutes after perispinal etanercept in patients with Alzheimer's disease was the initial clinical evidence suggesting the rapid synaptic and brain network effects of perispinal etanercept [6]. Subsequently, rapid improvement in neurological function after perispinal etanercept was reported in patients with multiple additional chronic brain disorders [6-10, 14, 16]. Rapid improvement in neglect of the left hemispace in the Clock-Drawing Test after perispinal etanercept is consistent with these previous clinical observations; the growing body of evidence documenting the existence of chronic brain inflammation after stroke and traumatic brain injury; independent evidence that neuroinflammation is associated with a reduction in functional connectivity in the brain; the rapid 
synaptic and neuronal effects produced by TNF in animal studies; and improvement in stroke outcomes after receiving etanercept in multiple animal models [6-12, 14, 16, 21-24]. Rapid improvement of hemispatial neglect after perispinal etanercept is also consistent with the concept that hemispatial neglect reflects brain network dysfunction and a disturbance in functional connectivity that is mediated by TNF.

This patient's pain description, along with the anatomic distribution of sensory loss and cold allodynia, with no other apparent cause of neuropathic pain, was pathognomonic of central post-stroke pain [25].

The existence of a therapeutic effect is supported by multiple factors, including:

- the rapid neurological improvement in this patient who had chronic, intractable post-stroke neurological dysfunction that had been present for 16 years;

- the pattern and immediacy of improvement;

- the replication of the same distinctive pattern of improvement in clock drawing (immediate resolution of neglect of the left hemispace) in multiple post-stroke patients;

- the concurrent improvement in chronic, central poststroke pain, in addition to improvement in hemispatial neglect, immediately following perispinal etanercept injection;

- the known role of TNF in modulating synaptic function, including synaptic strength and synaptic scaling;

- the known association of inflammation and decreased functional connectivity in the brain in other brain disorders.

The striking pattern of immediate improvement in clock drawing documented in this patient with chronic, previously intractable, central post-stroke pain, chronic post-stroke fatigue, and left hemispatial neglect is most consistent with rapid restoration of brain functional connectivity. This evidence suggests hemispatial neglect may be caused by TNFmediated network dysfunction and impairment in functional connectivity that remains reversible, even years after stroke. This evidence also suggests that central post-stroke pain may be mediated by TNF.

Functional magnetic resonance scanning and positron emission tomographic studies to image brain functional connectivity and neuroinflammation when studying therapeutics that target neuroinflammation in basic science studies and clinical trials may add to our understanding of the nature of chronic post-stroke neurological dysfunction.

\section{Compliance with Ethical Standards}

Conflicts of interest Edward Tobinick declares he holds multiple US and international patents covering the use of perispinal etanercept to treat post-stroke neurological dysfunction and other neurological dis- orders, receives royalties from these patents, and conducts a private medical practice utilizing perispinal etanercept.

Funding No funding was received in connection with this report. The author is the sponsor of Open Access.

Informed Consent Informed consent was obtained for the treatment of this patient. Treatment was performed as part of our usual practice of medicine and was not performed as part of a research study. Written consent was obtained for the publication of this case report.

Open Access This article is distributed under the terms of the Creative Commons Attribution-NonCommercial 4.0 International License (http://creativecommons.org/licenses/by-nc/4.0/), which permits any noncommercial use, distribution, and reproduction in any medium, provided you give appropriate credit to the original author(s) and the source, provide a link to the Creative Commons license, and indicate if changes were made.

\section{References}

1. Jackson JH. Case of large cerebral tumour without optic neuritis and with left hemiplegia and imperception. Royal London Opthalmic Hospital Reports. 1876;8.

2. He BJ, Snyder AZ, Vincent JL, Epstein A, Shulman GL, Corbetta $\mathrm{M}$. Breakdown of functional connectivity in frontoparietal networks underlies behavioral deficits in spatial neglect. Neuron. 2007;53(6):905-18.

3. Baldassarre A, Ramsey L, Hacker CL, Callejas A, Astafiev SV, Metcalf NV, et al. Large-scale changes in network interactions as a physiological signature of spatial neglect. Brain. 2014;137(Pt 12):3267-83.

4. Agrell B, Dehlin O. The clock-drawing test. Age Ageing. 1998;27:399-403.

5. Eknoyan D, Hurley RA, Taber KH. The clock drawing task: common errors and functional neuroanatomy. J Neuropsychiatry Clin Neurosci. 2012;24(3):260-5.

6. Tobinick EL, Gross H. Rapid cognitive improvement in Alzheimer's disease following perispinal etanercept administration. J Neuroinflammation. 2008;5:2.

7. Tobinick E. Rapid improvement of chronic stroke deficits after perispinal etanercept: three consecutive cases. CNS Drugs. 2011;25(2):145-55

8. Tobinick E, Kim NM, Reyzin G, Rodriguez-Romanacce H, DePuy V. Selective TNF inhibition for chronic stroke and traumatic brain injury: an observational study involving 629 consecutive patients treated with perispinal etanercept. CNS Drugs. 2012;26(12):1051-70.

9. Ignatowski TA, Spengler RN, Dhandapani KM, Folkersma H, Butterworth RF, Tobinick E. Perispinal etanercept for post-stroke neurological and cognitive dysfunction: scientific rationale and current evidence. CNS Drugs. 2014;28(8):679-97.

10. Tobinick E, Rodriguez-Romanacce H, Levine A, Ignatowski TA, Spengler RN. Immediate neurological recovery following perispinal etanercept years after brain injury. Clin Drug Investig. 2014;34(5):361-6.

11. Tobinick E. Perispinal etanercept advances as a neurotherapeutic. Expert Rev Neurother. 2018;18(6):453-5.

12. Shi K, Tian DC, Li ZG, Ducruet AF, Lawton MT, Shi FD. Global brain inflammation in stroke. Lancet Neurol. 2019. https://doi. org/10.1016/S1474-4422(19)30078-X (Epub 8 Jul 2019). 
13. Clark IA, Alleva LM, Vissel B. The roles of TNF in brain dysfunction and disease. Pharmacol Ther. 2010;128(3):519-48.

14. Clark IA, Vissel B. A neurologist's guide to tnf biology and to the principles behind the therapeutic removal of excess TNF in disease. Neural Plast. 2015;2015:358263.

15. Tobinick E, Gross H, Weinberger A, Cohen H. TNF-alpha modulation for treatment of Alzheimer's disease: a 6-month pilot study. MedGenMed. 2006;8(2):25.

16. Tobinick EL. Perispinal delivery of CNS drugs. CNS Drugs. 2016;30(6):469-80.

17. Tobinick EL, Chen K, Chen X. Rapid intracerebroventricular delivery of $\mathrm{Cu}$-DOTA-etanercept after peripheral administration demonstrated by PET imaging. BMC Res Notes. 2009;2:28.

18. Tobinick E. The cerebrospinal venous system: anatomy, physiology, and clinical implications. MedGenMed. 2006;8(1):53.

19. LaMacchia ZM, Spengler RN, Jaffari M, Abidi AH, Ahmed T, Singh N, et al. Perispinal injection of a TNF blocker directed to the brain of rats alleviates the sensory and affective components of chronic constriction injury-induced neuropathic pain. Brain Behav Immun. 2019;82:93-105.

20. Cumming TB, Mead G. Classifying post-stroke fatigue: optimal cut-off on the Fatigue Assessment Scale. J Psychosom Res. 2017;103:147-9.
21. Youn DH, Wang H, Jeong SJ. Exogenous tumor necrosis factoralpha rapidly alters synaptic and sensory transmission in the adult rat spinal cord dorsal horn. J Neurosci Res. 2008;86(13):2867-75.

22. Nygard M, Lundkvist GB, Hill RH, Kristensson K. Rapid nitric oxide-dependent effects of tumor necrosis factor-alpha on suprachiasmatic nuclei neuronal activity. NeuroReport. 2009;20(2):213-7.

23. Clausen BH, Degn M, Martin NA, Couch Y, Karimi L, Ormhoj $\mathrm{M}$, et al. Systemically administered anti-TNF therapy ameliorates functional outcomes after focal cerebral ischemia. J Neuroinflamm. 2014;11:203.

24. Zhang BF, Song JN, Ma XD, Zhao YL, Liu ZW, Li P, et al. Huang, Etanercept alleviates early brain injury following experimental subarachnoid hemorrhage and the possible role of tumor necrosis factor-alpha and c-Jun N-terminal kinase pathway. Neurochem Res. 2015;40(3):591-9.

25. Flaster M, Meresh E, Rao M, Biller J. Central poststroke pain: current diagnosis and treatment. Top Stroke Rehabil. 2013;20(2):116-23.

26. Breschet G. Recherches anatomiques physiologiques et pathologiques sur le système veinuex. Paris: Rouen fraeres; 1829. 